\title{
The reversal index (RI) as a joint function of drive and incentive level'
}

ROBERT L. GOSSETTE AND PATRICIA HOOD

COMPARATIVE ANIMAL BEHAVIOR LABORATORY, HOFSTRA UNIVERSITY

The spatial reversal performance of pigeons were studied in a formbox task under two levels of motivation and two levels of incentive. While both absolute error scores and latency were found to be significantly related to both $D$ and $\mathrm{K}$, the reversal index (RI) was found to be insensitive to both variables.

In the comparative analysis of behavior one of the major puzzles has been the failure to find significant inter-species differences of taxonomic import with traditional laboratory measures of learning (Warren, 1965). Until recently only learning set, among a variety of measures, had been found to yield any consistent inter-species differences, and that largely among certain primate groups. Unfortunately, learning set appears to be limited in range of applicability across vertebrates due to its intrinsic difficulty. Attention has now turned to a closely related procedure, successive discrimination reversal (SDR). SDR presents a far less difficult task; it is sensitive to inter-species differences across a much wider range of vertebrates (Gossette, Gossette, \& Riddell, 1966; Gossette, 1966). However, obtaining SDR measures tends to be quite time consuming and tedious. Rajalakshmi \& Jeeves (1965) have suggested a greatly abbreviated reversal measure, requiring only one reversal of an original discrimination. From this data the reversal index (RI), the ratio of errors on the original discrimination and its reversal, is obtained. Reviewing the available literature, these writers demonstrated that $\mathrm{RI}$ indices were sensitive to inter-species differences across several mammalian species. More recently similar findings were reported for a wider range of avian and mammalian species (Gossette \& Gossette, 1966).

However, all cross-species comparisons, on any task, are subject to one serious, but as yet empirically unevaluated, criticism. Obtained inter-species performance differences may be in part or largely due to differences in either motivational (D) or incentive (K) level, or both. As yet no information is available as to whether differences in either variable can influence RIs. Accordingly, the present study was designed to determine if variation in either $D$ or $K$ level can control the value of the reversal index.

Subjects

Sixteen adult pigeons of homing stock served as Ss. All Ss had been previously maintained in the laboratory for at least two months prior to testing. Four Ss were randomly assigned to each of the following four experimental conditions: High D-high $\mathrm{K}$, low D-high $\mathrm{K}$, high $\mathrm{D}$-low $\mathrm{K}$, low $\mathrm{D}$-low $\mathrm{K}$. The two values of $D$ chosen were $10 \%$ and $30 \%$ ad lib weight reductions. The two values of $K$ selected were set at 1 and 4 grains of pigeon ration.

Apparafus

A formboard box, described earlier (Gossette \& Cohen, 1966), was employed for reversal measurement. Two white, round blocks served as stimuli. Ss were required to peck a block, uncovering a foodwell, to obtain a food reward. Reinforcement was contingent upon responding to the correct position.

\section{Procedure}

All Ss were maintained on a free feeding schedule for about one month to establish ad lib weights. Then Ss were randomly assigned to the two D groups. Both groups were placed on deprivation schedules adjusted to keep their body weights at $70 \%$ and $90 \%$ of their ad lib weights. During this time each $\mathrm{S}$ was habituated to the test chamber, and trained to eat from the foodwells. As assigned weight reductions were attained, $S$ was trained to peck a block to obtain food from the underlying foodwell. Ss were given equal training to each block position. Training on Problem 1, original discrimination, was then initiated, with responding to the non-preferred position reinforced. When a criterion of two or fewer errors on a given day's session of 20 trials was achieved, Problem 2, position reversal, training was started, and continued to the same criterion. Non-correction was used throughout. Results and Discussion

$\mathrm{RI}$ indices were obtained for each $\mathrm{S}$ by dividing its Problem 2 error score by its Problem 1 error score. The mean RI values for each of the four experimental conditions are shown in Table 1. Analysis of these data by Kruskal-Wallis test failed to reveal any significant differences $(p>5)$. Thus the RI index appears to be relatively insensitive to variation in either D or K. A similar analysis of the absolute error scores did, however, reveal differences that were significant for Problem $1(p<.02)$. While not significant, the differences on Problem $1(p<.6)$ were in the same direc-

Table 1. RIs and mean errors and intra-session latencies for problems 1 and 2 for each drive-incentive condition.

\begin{tabular}{lccccc}
$\begin{array}{l}\text { Drive-incentive } \\
\text { condition }\end{array}$ & RI & $\begin{array}{c}\text { Problem } \\
\text { 1 errors }\end{array}$ & $\begin{array}{c}\text { Problem } \\
\text { 1 errors }\end{array}$ & $\begin{array}{c}\text { Problem } \\
\text { 1 latency }\end{array}$ & $\begin{array}{c}\text { Problem } \\
\text { 2 latency }\end{array}$ \\
\hline HD-HK & 2.67 & 26.0 & 56.5 & 9.4 & 10.0 \\
HD-LK & 2.80 & 47.8 & 99.8 & 15.7 & 19.1 \\
LD-HK & 2.21 & 19.8 & 39.3 & 15.7 & 15.8 \\
LD-LK & 2.44 & 30.5 & 91.8 & 32.9 & 51.8 \\
\hline
\end{tabular}


tion as on Problem 2. That is, mean errors (Table 1) tend to increase with increasing $D$, but decrease with increasing $K$. As a further check for $D$ and $K$ effects, the mean intra-sessional latencies were analyzed by Kruskal-Wallis test. Differences in latency were clearly significant $(p<.05)$ for both problems. Mean latency (Table 1) decreases with increase in both $\mathrm{K}$ and $\mathrm{D}$.

The inverse relation between error and latency measures is of interest in light of the controversy (Eysenck, 1957) concerning the effect of D upon choice measures. According to Eysenck's view the elevated errors would indicate that D for the $30 \%$ group was excessive, e.g., beyond some optimal value. In Spence's view the effect of increased D would presumably serve to increase the occurrence of irrelevant or competing responses that interfere with correct responding. While the present data provide no direct confirmation for either view, it is of interest to note that there is little change in the relative difference in error scores between the two D groups across Problems 1 and 2 . The effect of varying $D$ is roughly constant across both problems, despite the large negative transfer, e.g., competing response from Problem 1, shown on Problem 2.

One major requirement of any behavior measure to be employed in the calibration of inter-species differences is that it not reflect variation in task or procedural variables inherent in the measurement operation itself. Rajalakshmi and Jeeves in their review of previous work argue that the $R I$ is independent of task difficulty, but further direct experimental confirmation would appear to be required. However, the failure of either $D$ or $K$ to significantly control RI, though exerting a strong influence upon the absolute error scores upon which the RI is based, lends new support to the value of $\mathrm{RI}$ for cross-species comparisons.

\section{References}

Eysenck, H. J. The dynamics of anxiety and hysteria. London: Routledge and Kegan Paul, 1957.

Gossette, R. Comparison of successive discrimination reversal performances across 14 different avian and mammalian species. Amer. Zoologist, 1966, 6, (Abstract).

Gossette, R., \& Cohen, H. Error reduction by pigeons on a spatial successive reversal task under conditions of non-correction. Psychol. Rep., 1966, 18, 367-370.

Gossette, R., Gossette, Madeleine, \& Riddell, W. Comparisons of successive discrimination reversal performances among closely and remotely related avian species. Anim. Behav., 1966, 14, 560-564.

Rajalakshmi, R., \& Jeeves, $M$. The relative difficulty of reversal learning (reversal index) as a basis of behavioral comparisons. Anim. Behav., 1965, 13, 203-211.

Warren, J. M. Comparative psychology of learning. In Annual review of psychology, Vol. 16. Palo Alto, Calif.: Annual Reviews, Inc., 1965.

\section{Notes}

1. Supported in part by NSF grant No. GB-4799 awarded to the senior author.

Reply to Evans by Leslie Solyom

The primary result reported by Solyom, Beaulieu, and Enesco was that RNA injected animals bar pressed at a significantly higher rate than control animals during VI training and extinction, but not during CRF training. Lack of clarity in our paper seems responsible for Evans' question as to whether RNA treated rats acquire a bar pressing response more rapidly than control animals, and whether they show a subsequent resistance to extinction. The bar pressing response was acquired to criterion during master training, but these data were not included in our paper. On receiving Evans' letter, we analyzed this data and found that the whole RNA group showed a faster acquisition of the bar pressing response than did the saline group. The proportion of whole RNA animals who reached criterion on the first day of master training was greater than the proportion of saline animals who did so $\left(X^{2}=4.7, d f=1, p<0.05\right)$.

In interpreting the results of extinction, we failed to make explicit that while the whole RNA group bar pressed significantly more during the five day extinction period, they also exhibited a more rapid decline of response rate (see extinction curve for last three days).

Without doubt, stimulant drugs enhance the tendency to respond, but we would like to point out that these drugs also enhance activity, an effect which has notbeen found with RNA (Corson \& Enesco, 1966; Wagner etal, 1966).

Like Evans, we also feel that the interpretation of our results is far from being unequivocal. The hydrolized RNA group, for instance, was significantly better than the saline group during CRF training but in no other phase of the experiment. Since we had found a significantly higher bar pressing in the whole RNA group during VI training, then by exclusion of such factors as greater motivation (increased thirst, Corson \& Enesco, 1966) and greater activity, we interpreted this result as suggestive evidence of an RNA effect on learning.

If RNA affects only performance, then the rate of an already learned response should be increased by RNA administration, and not by saline. In a recently completed study, where this proposition was subjected to investigation (unpublished data), we failed to find an increase in rate of bar pressing for either group.

In the light of presently available evidence, however, it indeed may be difficult to state whether RNA affects learning or performance. The experiment which Evans suggests would be of great interest in clarifying this point. 